\title{
Common Factors Leading to Tooth Extraction - A Cross Sectional Study in A Tertiary Care Hospital
}

\section{Syed M Abdullah Salman ${ }^{1}$, Shaheen Ahmed ${ }^{2}$, Yashfika Abdul Bari ${ }^{3 *}$, Omair Ghory $^{4}$, Faran Farooq ${ }^{4}$ and Maryam Younus $^{5}$}

${ }^{1}$ Lecturer, Dow University of Health Sciences, Pakistan

${ }^{2}$ Associate Professor, Dow University of Health Sciences, Pakistan

${ }^{3}$ Research Analyst, College of Physician and Surgeons, Pakistan

${ }^{4}$ Dow University of Health Sciences, Pakistan

${ }^{5}$ College of Physicians and Surgeons, Dow University of Health Sciences, Pakistan

*Corresponding Author: Yashfika Abdul Bari, Research Analyst, College of Physician and Surgeons, Pakistan.

Received: June 20, 2019; Published: July 11, 2019

DOI: $10.31080 /$ ASDS.2019.03.0588

\begin{abstract}
Background: Tooth extraction causes a negative impact on the quality of life. It does not only affect speech and mastication but also affects overall well-being. There are numerous factors for tooth extraction. Tooth extraction is gaining popularity worldwide because tooth loss remains an imperative subject in public health.

Objective: To determine the frequency of different factors leading to tooth extraction in patients visiting tertiary care hospital.

Material and Methods: The cross-sectional study was carried out in Dow University of Health Sciences, Pakistan. Adult patients of age 20 to 60 years of either gender with permanent teeth presenting with pain and sensitivity were included in the study through non-probability consecutive sampling technique. All the details were recorded in a well-designed performa. Sample size calculation was done using the WHO sample size calculator. Data were analyzed through SPSS software.

Results: The mean age +/-SD of subjects was $41.64 \pm 15.02$ (8-85) years. Out of 520 patients, $49.2 \%$ of patients had their extraction in the lower arch whereas $44.6 \%$ of patients had extractions in the upper arch. In addition, $56.4 \%$ of patients had their molar tooth extracted. $77.5 \%$ of patients had caries and \% patients had periodontal disease, $7.9 \%$ patients that underwent tooth extraction had hypertension, and $2.9 \%$ had diabetes. Patients with age less than 40 years had statistically significant relation with caries. And patients with more than 40 years had statistically significant relation with periodontal disease. $(\mathrm{P}$ value $=<0.05)$.

Conclusion: It is recommended to have proper screening, regular monitoring and strategic planning of whole dentition for caries, periodontal disease, diabetes and hypertension among the general population so that there is regular dental check-up. This approach could lead to decrease in morbidity and mortality of dentition. We also recommend improved accessibility of oral healthcare facilities, intensification of oral healthcare awareness campaigns, and fluoridation of community water supply.
\end{abstract}

Keywords: Extraction; Caries; Periodontal Disease; Diabetes; Hypertension

\section{Introduction}

Tooth loss is one of the major social and aesthetic embarrassments. It causes negative impact on quality of life. It's not only affect speech and mastication but also affects overall well- being. It is very substantial to collect data from all over the world regarding dental status and keeping it accurate for community awareness [1]. In the past decade, researches have shown that tooth extraction is gaining popularity worldwide because tooth loss remains an imperative subject in public health. 
There are numerous causes for tooth extraction such us caries, periodontal disease, orthodontic treatment, trauma, prosthetic procedures, impacted tooth, restoration failure, root canal treatment failure, financial issue and presence of supernumerary tooth [2-5].

An epidemiological review [6] has been carried out to ascertain the cause of tooth extraction. The review showed that caries and periodontal disease were most prevalent cause of tooth extraction and other studies reported same in Brazillian [7], Greece [8], Iranian [9] population.

Several epidemiological surveys also concluded that dental caries remains most important reason for tooth extraction [3,1012]. These surveys also reported that despite caries being most frequent cause leading to tooth extraction, periodontal disease sets the bar rather high as increasing age leads to increase in periodontal problems.

Various studies also conducted in Lahore and Karachi also reported that patients who required extraction had grossly carious tooth $[13,14]$. Moreover, orthodontic reason is principal reason for extraction in people younger than 20 years old [15-17]. Unfortunately, tooth extraction is last resort of choice where all treatments for tooth savage have come to failure and is irreversible type of dental management. Every dentist should give great insight before carrying out extraction.

However, despite being non-conservative dental treatment, it has been carrying out successfully at first priority in not only in developing parts of the world but developed countries under great financial burden opt to get their tooth extracted $[8,18]$. There is scarcity of data on reasons of tooth extraction in patients with different systemic diseases including diabetes mellitus (DM), hypertension, bone disease, peptic ulcer, and cancer. Studies have shown that there is greater risk of tooth morbidity in patients with diabetes and hypertension [19-21].

Hence the aim of this study is to evaluate different factors leading to extraction of tooth and find out if there is any statistical relation among these factors. By identifying the main factors for tooth loss, it may be possible to limit future extractions by implementation of efficient programs and increase the level of awareness among all populations and treating systemic factors that contribute to teeth injury and death.

\section{Material and Methods}

The cross sectional study was carried out from the period of February 2018 to December 2018 in oral and maxillofacial surgery department of Dow University of Health Sciences, Pakistan. Following ethical approval and consent from patients, subjects were enrolled through non-probability consecutive sampling technique.

Inclusion criteria

1. Adult patients of age 20 to 60 years.

2. Both gender

3. Permanent teeth

4. Patients requiring extraction.

\section{Exclusion criteria}

$\begin{array}{ll}\text { 1. } & \text { Deciduous teeth } \\ \text { 2. } & \text { Poor oral hygiene } \\ \text { 3. } & \text { Betel nut and quid chewers } \\ \text { 4. } & \text { Smokers } \\ \text { 5. } & \text { Congenitally missing teeth } \\ \text { 6. } & \text { Alcohol users }\end{array}$

All the details were recorded in a well-designed Performa. Perform was divided into 5 categories; namely; age, gender, tooth type, systemic condition and reasons for tooth extraction. Sample size was calculated using WHO sample size calculator based on frequency of endodontic failure as $2.7 \%$, [22] margin of error as $1.4 \%$ and $95 \%$ confidence level. The estimated sample size came out as 515. Data was analyzed through SPSS software. Frequencies and percentages were calculated. Chi square test was applied keeping significance level $(\mathrm{P})<0.05$.

\section{Results}

Results are illustrated through charts, graphs and table.

Chart 1 and 2 demonstrate patient's age and gender recruited in the study. The mean ages $+/$-SD of subjects were $41.64 \pm 15.02$ (8-85) years.

Graph 1 shows dental demographics of patients enrolled in the study. It shows that $49.2 \%$ patients had their extraction in lower arch whereas $44.6 \%$ patients had extractions in upper arch. In addition, $56.4 \%$ patients had their molar tooth extracted. 


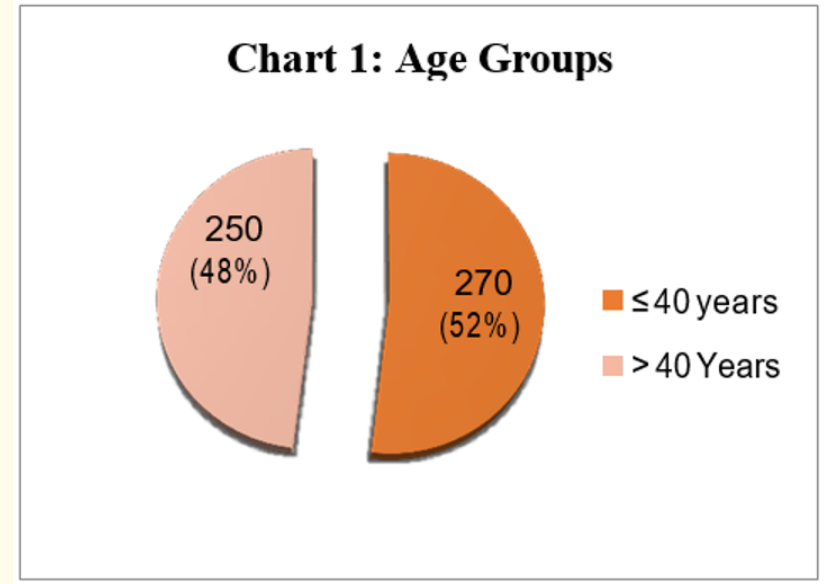

Chart 1

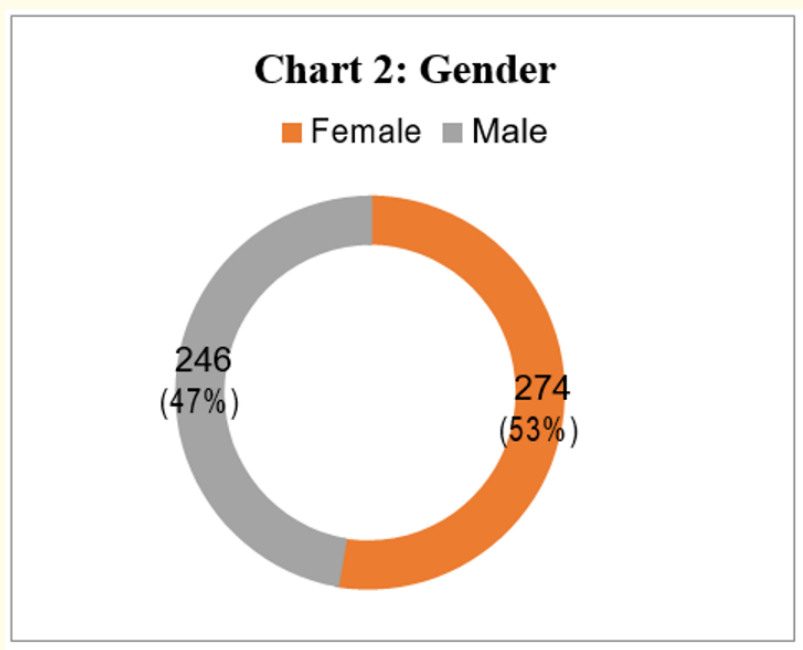

Chart 2

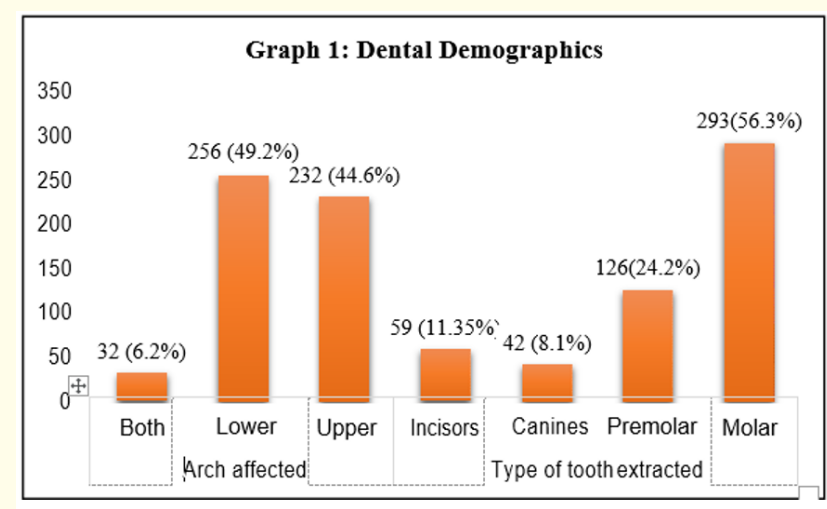

Graph 1
Graph 2 and 3 explains different dental and systemic factors leading tooth extraction respectively. It shows that out of 520 subjects $403(77.5 \%)$ patients had caries and 84 patients had periodontal disease (16.2\%). Moreover, 41 (7.9\%) patients that underwent tooth extraction had hypertension, and15 $(2.9 \%)$ had diabetes.

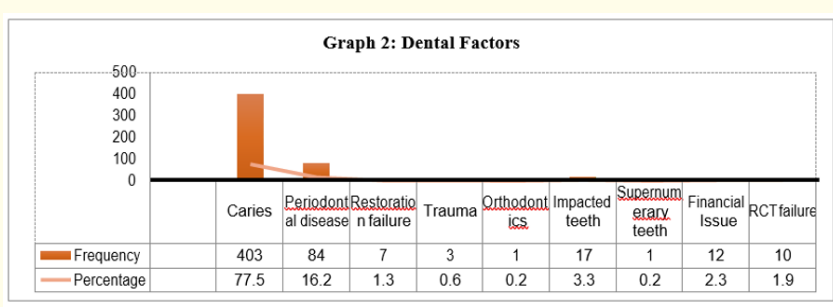

Graph 2

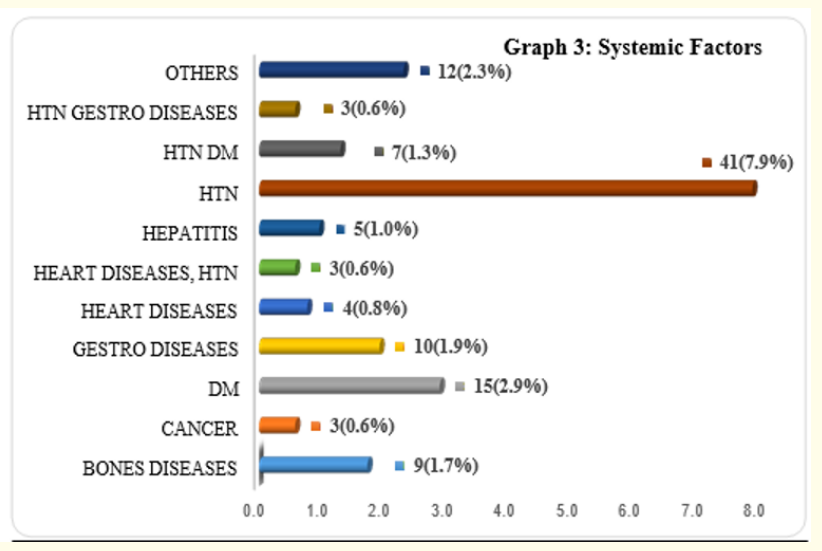

Graph 3

Table 1 shows relationship of dental factors with age and gender and also relationship between dental and systemic factors. Data shows that there is statistically significant relation between caries, periodontal disease and age. Patients with age less than 40 years had statistically significant relation with caries. And patients with more than 40 years had statistically significant relation with periodontal disease ( $\mathrm{P}$ value $=<0.05$ ).

\section{Discussion}

Tooth extraction as a management in dental rehabilitation has gained lot of popularity. Every other patient chose extraction over root canal treatment as it is single visit and cost effective. Despite, there are other factors also that leads to ultimate tooth extraction. As a dentist, it should be our primary responsibility to execute tooth survival measures and treat the factors leading to extraction. Hence this study aims to identify those factors leading to tooth extraction. 


\begin{tabular}{|l|l|l|l|l|l|l|}
\hline \multicolumn{7}{|c|}{ Age and Gender } \\
\hline \multirow{2}{*}{ Factors } & Age Group & \multicolumn{2}{l}{ Gender } \\
\cline { 2 - 7 } & $\leq 40$ years & $>40$ years & P-value & Male & Female & P-Value \\
\hline Caries & $222(82.2 \%)$ & $181(72.4 \%)$ & 0.007 & $169(68.7)$ & $234(85.4 \%)$ & 0.000 \\
\hline Periodontal Disease & $14(5.2 \%)$ & $70(28 \%)$ & 0.000 & $57(23.2 \%)$ & $27(9.9 \%)$ & 0.000 \\
\hline Restoration Failure & $6(2.2 \%)$ & $1(0.4 \%)$ & 0.072 & $6(2.4 \%)$ & $1(0.4 \%)$ & 0.04 \\
\hline Trauma & $2(0.7 \%)$ & $1(0.4 \%)$ & 0.608 & $3(1.2 \%)$ & $0(0 \%)$ & 0.067 \\
\hline Orthodontics & $1(0.4 \%)$ & $0(0 \%)$ & 0.335 & $0(0 \%)$ & $1(0.4 \%)$ & 0.343 \\
\hline Impacted Teeth & $15(5.6 \%)$ & $2(0.8 \%)$ & 0.002 & $9(3.7 \%)$ & $8(2.9 \%)$ & 0.636 \\
\hline Supernumerary Tooth & $1(0.4 \%)$ & $0(0 \%)$ & 0.335 & $1(0.4 \%)$ & $0(0 \%)$ & 0.291 \\
\hline Financial Issue & $8(3 \%)$ & $4(1.6 \%)$ & 0.301 & $3(1.2 \%)$ & $9(3.3 \%)$ & 0.117 \\
\hline RCT failure & $8(3 \%)$ & $2(0.8 \%)$ & 0.073 & $7(2.8 \%)$ & $3(1.1 \%)$ & 0.147 \\
\hline
\end{tabular}

Table 1: Relation of Dental Factors Leading to Tooth Extraction.

In the present study, results showed that majority of the patients that had undergone extraction were less than 40 years old. These results are analogous to few studies [7,8,23]. Our results also explains that permanent first molar tooth is most commonly affected in patients following premolar, incisors and canines similar to study conducted in Tehran [9].

In one study, it is well reported that patients that had their tooth extracted has vertical root fracture and it was reported that first permanent molars were mostly affected [24]. The results of this study also showed that there was more number of females for tooth extraction which is self-explanatory that there are higher chances of tooth extraction in females as compare to males. Lastly, our study results also showed that lower arch is more commonly affected as compare to upper arch which is also similar to the findings of Al-Ansari AA., et al. study, Montandon AAB., et al. study, Baqain ZH., et al. study, and Yoshino K., et al. study [1,7,12,24].

In contrast with the findings of Touré B., et al. study, he reported that almost $40 \%$ of patients had periodontal disease followed by endodontic failure in $20 \%$ patients $[25,26]$. Our study showed that most patients had caries followed by periodontal disease. This is equivalent to findings of Chrysanthakopoulos NA., et al. [8] study, Montandon AAB., et al. [7] study, and Jafarian M., et al. [9] study. The findings of our study is also relatable a pilot study [27] that also reported caries as a most frequent cause. Moreover, our findings are also comparable to few more studies conducted in Pakistan and Saudi Arabia [13, 14, 28].
Other factors like orthodontic extractions did not contribute much in this study, which is comparable to other studies [29, 30] On contrary, in a study, trauma contributed as third most leading factor towards exodontia [31] Other factors leading to extraction contributed insignificantly. This small proportion is also comparable to Alesia K., et al. study [32].

Studies have also found out influence of diabetes mellitus and hypertension. Our results showed that majority of patients visited to dental clinics had either diabetes or hypertension. The results put emphasis to local statistics of diabetes and hypertension. Hence, it can be said that diabetes and hypertension is also a leading factor to tooth extraction. Our study showed that diabetic patients are at higher risk of developing caries and periodontal disease. The results of our study are analogous to Dikbas I., et al. study, Offenbacher S., et al. study, Choe H., et al. study, Jimenez M., et al. study, Preshaw P., et al. study, and Latti BR., et al. study [25,33-37].

\section{Conclusion}

In a nutshell, it is recommended to have proper screening of for dental and systemic factors. Majority patients had lost their teeth due to caries which was followed by periodontal disease. Moreover, strategic planning for awareness of diabetes and hypertension should be established among general population so that there is regular dental check-up. This approach could lead to decrease morbidity and mortality of dentition. We also recommend improved accessibility of oral healthcare facilities by deploying mobile dental facilities, intensification of oral healthcare awareness campaigns, 
increased recruitment of dental experts, and fluoridation of community water supply.

\section{Bibliography}

1. Al-Ansari AA. "Prevalence, severity, and secular trends of dental caries among various Saudi populations: A literature review". Saudi Journal of Medicine and Medical Sciences 2.3 (2014): 142-150.

2. Chestnutt IG BV sand Taylor MM. "Reasons for tooth extraction in Scotland". Journal of Dentistry 28.4 (2000): 295-297.

3. Richards W AJ., et al. "Reasons for tooth extraction in four general dental practices in South Wales". British Dental Journal 198.5 (2005): 275-278.

4. Stephens RG KS and Jarvis AM. "A study of the reasons for tooth extraction in a Canadian population sample". Journal of the Canadian Dental Association 57.6 (1991): 501-504.

5. Szabo J SI and Kiralyfalvi L. "Survey of reasons for tooth extraction in the framework of government-sponsored dentistry". Fogorvosi szemle 84.6-7 (1991): 161-166.

6. PPTWOHR. 21st cioohit, Health ctaotWGO, PCDOE 1 (2003): 3-23S.

7. Montandon AAB., et al. "Prevalence and reasons for tooth loss in a sample from a dental clinic in Brazil". International journal of dentistry (2012).

8. Chrysanthakopoulos NA. "Reasons for extraction of permanent teeth in Greece: a five-year follow-up study". International dental journal 61.1 (2011): 19-24

9. Jafarian M and Etebarian A. "Reasons for extraction of permanent teeth in general dental practices in Tehran, Iran". Medical Principles and Practice 22.3 (2013): 239-244.

10. Quteish Taani D. "Periodontal reasons for tooth extraction in an adult population in Jordan". Journal of oral rehabilitation 30.1 (2003): 110-112.

11. Sayegh A., et al. "Pattern of tooth loss in recipients of free dental treatment at the University Hospital of Amman, Jordan". Journal of oral rehabilitation 31.2 (2004):124-130.

12. Baqain ZH., et al. "Dental extraction for patients presenting at oral surgery student clinic". Compendium of continuing education in dentistry (Jamesburg, NJ: 1995) 28.3 (2007):146-150.
13. Haseeb M., et al. "Causes of tooth extraction at a tertiary care centre in Pakistan". JPMA-Journal of the Pakistan Medical Association 62.8 (2012): 812.

14. Naz F. "Reasons for extraction in permanent dentition A study in a tertiary care setting in Pakistan". Java Platform Debugger Architecture 20.04 (2011): 235-238.

15. McCaul L., et al. "The reasons for the extraction of various tooth types in Scotland: a 15-year follow up". Journal of dentistry 29.6 (2001): 401-407.

16. Hull P., et al. "The reasons for tooth extractions in adults and their validation". Journal of dentistry 25.3-4 (1997): 233-237.

17. Peck S and Peck H. "Frequency of tooth extraction in orthodontic treatment". American Journal of Orthodontics and Dentofacial Orthopedics 76.5 (1979): 491-496.

18. Locker D., et al. "Income, dental insurance coverage, and financial barriers to dental care among Canadian adults". Journal of public health dentistry 71.4 (2011): 327-334.

19. Wang C-H., et al. "Impact of diabetes mellitus, hypertension, and coronary artery disease on tooth extraction after nonsurgical endodontic treatment". Journal of endodontics 37.1 (2011): 1-5.

20. Fouad AF and Burleson J. "The effect of diabetes mellitus on endodontic treatment outcome: data from an electronic patient record". The Journal of the American Dental Association 134.1 (2003): 43-51.

21. Britto LR., et al. "Periradicular radiographic assessment in diabetic and control individuals". Oral Surgery, Oral Medicine, Oral Pathology, Oral Radiology, and Endodontology 96.4 (2003): 449-452.

22. Al Ameer HM and Awad S. "Reasons for Permanent Teeth Extraction in Al-Madinah Al- Munawarah". Journal of Advances in Medicine and Medical Research 24.7 (2017): 1-6.

23. Silva Jr MF., et al. "Oral health condition and reasons for tooth extraction among an adult population (20-64 years old)". Ciência and Saúde Coletiva 22.8 (2017): 2693-2703.

24. Yoshino K., et al. "Prevalence of vertical root fracture as the reason for tooth extraction in dental clinics". Clinical oral investigations 19.6 (2015):1405-1409.

25. Dikbas I., et al. "Evaluation of reasons for extraction of crowned teeth: a prospective study at a university clinic". Acta Odontologica Scandinavica 71.3-4 (2013): 848-856. 
26. Touré B., et al. "Analysis of reasons for extraction of endodontically treated teeth: a prospective study". Journal of endodontics 37.11 (2011):1512-1515.

27. Byahatti SM and Ingafou MS. "Reasons for extraction in a group of Libyan patients". International dental journal 61.4 (2011): 199-203.

28. Alaboudi AK., et al. "Reasons for teeth extraction in governmental hospitals in Madinah City, Saudi Arabia”. IOSR Journal of Dental and Medical Sciences 15.07 (2016): 1-5.

29. Taiwo OA., et al. "Patterns and reasons for childhood tooth extraction in Northwest Nigeria". Journal of Pediatric Dentistry 2.3 (2014): 83-87.

30. Odusanya S. "Tooth loss among Nigerians: causes and pattern of mortality". International journal of oral and maxillofacial surgery 16.2 (1987): 184-189.

31. Saheeb B and Sede M. "Reasons and pattern of tooth mortality in a Nigerian Urban teaching hospital". Annals of African medicine 12.2 (2013):110-114.

32. Alesia K, Khalil HS. "Reasons for and patterns relating to the extraction of permanent teeth in a subset of the Saudi population". Clinical, cosmetic and investigational dentistry 5 (2013): 51.

33. Offenbacher S., et al. "Impact of tooth loss on oral and systemic health". General Dentistry 60.6 (2012): 494-500.

34. Choe H., et al. "Tooth loss, hypertension and risk for stroke in a Korean population". Atherosclerosis 203.2 (2009): 550-556.

35. Jimenez M., et al. "Type 2 diabetes mellitus and 20year incidence of periodontitis and tooth loss". Diabetes research and clinical practice 98.3 (2012): 494-500.

36. Preshaw P., et al. "Periodontitis and diabetes: a two-way relationship". Diabetologia 55.1 (2012): 21-31.

37. Latti BR., et al. "Evaluation of relationship between dental caries, diabetes mellitus and oral microbiota in diabetics". Journal of oral and maxillofacial pathology: JOMFP 22.2 (2018): 282.

Volume 3 Issue 8 August 2019

(C) All rights are reserved by Yashfika Abdul Bari., et al. 